\title{
Risk factors associated with preterm birth in the Gaza Strip: hospital- based case-control study
}

Kh. Abu Hamad, ${ }^{1}$ Y. Abed ${ }^{2}$ and B. Abu Hamad ${ }^{2}$

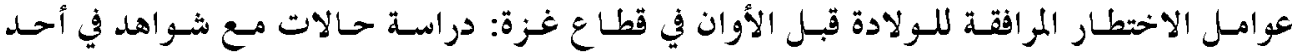

$$
\begin{aligned}
& \text { المستشفيات } \\
& \text { ختام أبو حملد، يمييى عابند، بسام أبو حمد }
\end{aligned}
$$

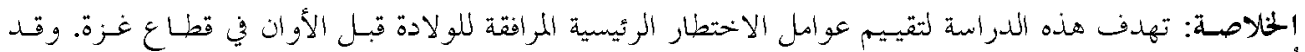

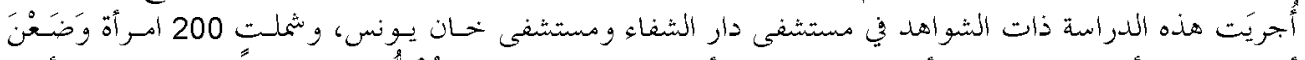

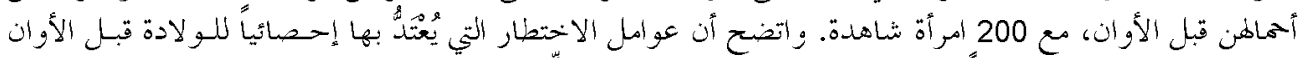

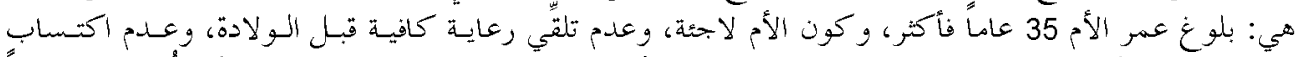

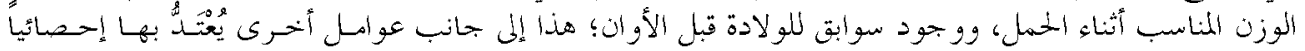

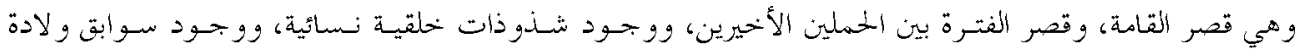

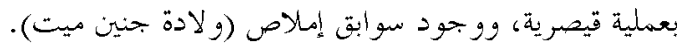

ABSTRACT This study aimed to assess the main maternal risk factors associated with preterm birth in the Gaza Strip. A hospital-based case-control study was carried out at El-Shifa and Khan-Younis hospitals with 200 women with preterm births and 200 control women. Significant risk factors for preterm birth were: maternal age $\geq 35$ years, being a refugee, inadequate antenatal care, failure to gain adequate weight during pregnancy and previous history of preterm birth. Other significant risk factors included: short stature, short interval between the last 2 pregnancies, presence of congenital gynaecological abnormalities, previous history of caesarean delivery and previous history of stillbirth.

Facteurs de risque associés aux naissances prématurées dans la Bande de Gaza : étude castémoins en milieu hospitalier

RÉSUMÉ Cette étude avait pour objectif d'évaluer les principaux facteurs de risque maternels associés aux naissances prématurées dans la Bande de Gaza. Une étude cas-témoins en milieu hospitalier a été menée dans les hôpitaux d'El-Shifa et de Khan-Younis auprès de 200 femmes ayant accouché avant terme et de 200 femmes témoins. Un âge maternel $\geq 35$ ans, un statut de réfugiée, la médiocrité de la prise en charge anténatale, l'insuffisance de la prise de poids pendant la grossesse et des antécédents de prématurité sont apparus comme autant de facteurs de risque significatifs de naissance prématurée. Figurent parmi les autres facteurs de risque importants une petite taille, la brièveté de l'intervalle génésique entre les 2 dernières grossesses, la présence de malformations congénitales de l'appareil gynécologique, des antécédents d'accouchement par césarienne et une histoire de mortinatalité.

\footnotetext{
Ministry of Health, Gaza, Palestine (Correspondence to Kh. Abu Hamad: khitam_hamad@yahoo.com). ${ }^{2}$ School of Public Health, Al-Quds University, Gaza, Palestine.

Received: 04/08/05; accepted: 13/10/05
} 


\section{Introduction}

Preterm birth continues to be the leading cause of perinatal and postnatal mortality and morbidity especially in developing countries, where health facilities are not only limited but are not functioning properly [1]. In spite of our knowledge about the problem, globally, preterm births are possibly one of the commonest causes of maternal and child health problems in developed societies [2]. According to Copper et al. preterm birth occurs in $7 \%$ to $11 \%$ of pregnancies but is responsible for $85 \%$ of neonatal deaths in normally formed infants who do not have any congenital anomalies [3]. Moreover, the provision of intensive care for extremely preterm newborns is expensive and preterm birth is considered a traumatic event [2].

Although risk factors for preterm birth have been commonly studied worldwide $[2,3]$, no systematic surveys have been conducted in the Gaza Strip. In view of the immense cost of preterm birth, high total fertility rate in the Gaza Strip, low economic status, lack of resources and the stresses of the political situation in Gaza Strip it is important to study the risk factors for preterm birth. It is also important in view of the uniqueness of the population - a high proportion are Palestinian refugees - and the known influence of social factors on preterm birth. This study was therefore carried out to determine the main risk factors that contribute to preterm birth in the Gaza Strip in order to inform suggestions for strategies to prevent preterm birth that are etiologically based and country specific.

\section{Methods}

A hospital-based case-control was carried out at the 2 main government hospitals in the Gaza Strip, El-Shifa and Khan-Younis hospitals, with matching for 2 variables: place of residence (governorate) and place of delivery. The study population consisted of newly delivered women and their babies. Every premature delivery (case) was matched with a fullterm delivery (control).

\section{Sample}

The sample size was determined using the statistical program Epi-info. The proposed sample size was 350 subjects. The actual sample size was increased to 424 subjects to compensate for non-responses, with a response rate of $94.3 \%$. Thus the study included 200 cases and 200 controls.

All women who delivered in the hospitals during the prescribed period (March to mid April 2002) were included as cases. Control women were randomly selected by taking the next fullterm delivery. The inclusion criteria were: for cases, clients who newly delivered a preterm baby (26-37 weeks gestation); for controls, clients who newly delivered a fullterm baby (37-42 weeks gestation). The exclusion criteria were: gestational age $<26$ weeks, postmature newborn infants, intrauterine fetal death and highly urgent cases.

\section{Data collection}

Data were collected through direct and indirect methods. Direct methods included biomedical measurements of weight and height for both women and their babies. Indirect data collection was done through highly structured interviews.

The following were included in the questionnaire: maternal personal and demographic data (age, address, governorate of residence, years of education and current occupation); maternal physical information (maternal height); socioeconomic information (nuclear or extended family and 
monthly income); past obstetric history (age at marriage, history of preterm delivery, history of abortion, history of congenital gynaecological problems, history of vaginal and cervical infections); antenatal care during pregnancy (total number of antenatal care visits attended, time of attending antenatal care); and newborn information (mode of delivery, weight, height, sex and health problems of newborn).

\section{Ethical procedures}

An official letter of approval to conduct the study was obtained from the authorized ethical committee in the Gaza Strip. An official letter of request was obtained from the Ministry of Health to conduct the study in the government hospitals. Every participant in the study received a complete explanation about the research, its purpose, confidentiality and sponsorship and every woman knew that participation in the research was optional and she had the right to refuse. After obtaining informed consent, clients were interviewed; confidentiality and privacy was maintained.

\section{Statistical analysis}

The collected data were entered into a computer using SPSS, version 8.0. The statistical relationship between the risk factors and preterm birth were assessed using the chisquared test and the odds ratio (OR) with 95\% confidence interval (CI) were calculated. Also the $t$-test was used to determine the difference between the means of cases and controls. Statistical level of significance used was 0.05 . In addition, logistic regression was done to predict the probability of having preterm birth.

\section{Constraints of the study}

The main constraints facing the researchers were the political situation during the data collection period; the Gaza Strip was divid- ed into separated isolated areas which made the movement of researchers between the 2 study locations difficult and sometimes even impossible.

\section{Results}

The study showed obvious variations in demographic factors, socioeconomic status, obstetric/gynaecological history, current obstetric information and maternal physical characteristics between the 2 groups.

\section{Demographic characteristics}

The study was carried out in the 5 geographical districts of the Gaza Strip. The majority of participants were from Gaza governorate (41.0\%) followed by North Gaza (19.0\%), Khan-Younis (17.0\%), Mid-zone (12.0\%) and Rafah (11.0\%).

The mean maternal age of all study participants was 26.7 years [standard deviation (SD) 6.5]. For cases the mean age was 27.0 years (SD 6.7), while for controls it was 26.1 years (SD 6.2). The majority of mothers were aged $18-34$ years $(77.4 \%$ for cases and $84.5 \%$ for controls), followed by the age group $\geq 35$ years; the fewest mothers were aged $<18$ years olds (Table 1 ). Using age group 18-34 years old as a base for comparison there was no difference in the prevalence of preterm birth between cases and controls (4.9\% versus $4.5 \%)$ among women aged $<18$ years or age $18-34$ years old $(95.1 \%$ versus $95.5 \%)\left(\chi^{2}=0.03, P=\right.$ 0.8 ). However, the prevalence of preterm birth was significantly higher in cases than in controls among women aged $\geq 35$ years $(19.4 \%$ versus $12.0 \%)\left(\chi^{2}=3.9, \bar{P}=0.04\right)$

Concerning citizenship, the prevalence of cases from refugees was also significantly higher than from Palestinian citizens; $63.0 \%$ of cases were refugees and $37.0 \%$ were Palestinian citizens, whereas 52.0\% 


\begin{tabular}{|c|c|c|c|c|c|c|c|c|}
\hline \multicolumn{9}{|c|}{$\begin{array}{l}\text { Table } 1 \text { Comparison between cases and controls by selected demographic and } \\
\text { obstetric variables }\end{array}$} \\
\hline \multirow[t]{2}{*}{ Variable $^{a}$} & \multicolumn{2}{|c|}{ Cases } & \multicolumn{2}{|c|}{ Controls } & \multicolumn{2}{|c|}{ Total } & \multirow[t]{2}{*}{$\chi^{2}$-value } & \multirow[t]{2}{*}{$P$-value } \\
\hline & No. & $\%$ & No. & $\%$ & No. & $\%$ & & \\
\hline \multicolumn{9}{|l|}{ Maternal age (years) } \\
\hline$<18$ & 8 & 4.0 & 8 & 4.0 & 16 & 4.0 & 3.9 & 0.13 \\
\hline $18-34$ & 154 & 77.4 & 169 & 84.5 & 323 & 81.0 & & \\
\hline$\geq 35$ & 37 & 18.6 & 23 & 11.5 & 60 & 15.0 & & \\
\hline \multicolumn{9}{|l|}{ Palestinian citizenship } \\
\hline Citizen & 74 & 37.0 & 96 & 48.0 & 170 & 42.5 & 4.9 & 0.026 \\
\hline Refugee & 126 & 63.0 & 104 & 52.0 & 230 & 57.5 & & \\
\hline \multicolumn{9}{|l|}{ Mode of conception } \\
\hline Spontaneous & 176 & 88.0 & 191 & 95.5 & 367 & 91.8 & 7.4 & 0.006 \\
\hline Medically induced & 24 & 12.0 & 9 & 4.5 & 33 & 8.2 & & \\
\hline \multicolumn{9}{|l|}{ No. of antenatal visits } \\
\hline$<4$ & 48 & 24.6 & 23 & 11.9 & 71 & 18.3 & 10.4 & 0.001 \\
\hline$\geq 4$ & 147 & 75.4 & 170 & 88.1 & 317 & 81.7 & & \\
\hline \multicolumn{9}{|c|}{ Mother's working status } \\
\hline Working & 13 & 6.5 & 9 & 4.5 & 22 & 5.5 & 0.7 & 0.3 \\
\hline Not working & 187 & 93.5 & 191 & 95.5 & 378 & 94.5 & & \\
\hline \multicolumn{9}{|l|}{ Birth outcome } \\
\hline Singleton & 171 & 85.5 & 196 & 98.0 & 367 & 91.8 & 20.6 & 0.000 \\
\hline Twins & 29 & 14.5 & 4 & 2.0 & 33 & 8.3 & & \\
\hline
\end{tabular}

of controls were refugees and $48.0 \%$ were citizens $\left(\chi^{2}=4.9, P=0.026\right)$ (Table 1$)$.

For all participants, years of education were 10.0 years (SD 3.5). For cases, the mean years of education were the same [10.0 years (SD 3.6)] as for controls [10.0 years (SD 3.4)]. The proportion of working women was $6.5 \%$ among cases and $4.5 \%$ among controls.

\section{Maternal physical characteristics}

The mean maternal height for the study population was $162.7 \mathrm{~cm}$ (SD 7.2). This was significantly lower for cases than controls

\begin{tabular}{|c|c|c|c|c|c|c|}
\hline \multirow[t]{2}{*}{ Variable } & \multicolumn{2}{|c|}{ Cases } & \multicolumn{2}{|c|}{ Controls } & \multirow{2}{*}{ t-test } & \multirow[t]{2}{*}{$P$-value } \\
\hline & No. & Mean (SD) & No. & Mean (SD) & & \\
\hline Maternal height $(\mathrm{cm})$ & 187 & $161.8(6.8)$ & 188 & $163.6(7.5)$ & 2.4 & 0.016 \\
\hline $\begin{array}{l}\text { Total weight gain during } \\
\text { pregnancy }(\mathrm{kg})\end{array}$ & 172 & $9.8(4.8)$ & 179 & $11.1(4.8)$ & 2.4 & 0.015 \\
\hline
\end{tabular}


[161.8 cm (SD 6.8) versus $163.6 \mathrm{~cm}(\mathrm{SD}$ 7.5)] $(t=2.4, P=0.016)$ (Table 2).

The mean increase in weight during pregnancy for cases was significantly lower than controls [9.8 $\mathrm{kg}(\mathrm{SD} 4.8)$ versus 11.1 $\operatorname{kg}(\operatorname{SD~4.8)}](t=2.4, P=0.015)$ (Table 2).

\section{Current pregnancy}

Regarding the mode of delivery, the percentage of women who had caesarean section (CS) deliveries was higher among cases $(36.0 \%)$ than controls $(32.5 \%)$.

The proportion of singleton births among all the study sample was $91.8 \%$, while multiple births (twins) were only $8.3 \%$. The rate of twin births was higher among cases than controls $\left(\chi^{2}=20.6, P<0.0001\right)(14.5 \%$ versus $2.0 \%$ ).

The mean gestational age for the offspring of the study sample was 36.8 gestational weeks (SD 3.4). For cases, the mean gestational age was 34.1 weeks (SD 2.6) and for controls 39.5 weeks (SD 1.4).

The prevalence of medically induced pregnancy (hormonal therapy and in vitro fertilization) was significantly higher among cases $(12.0 \%)$ than controls $(4.5 \%)$ $\left(\chi^{2}=7.4, P<0.006\right)$ (Table 1).

Of women who attended $<4$ antenatal visits, $24.6 \%$ were cases and $11.9 \%$ were controls $\left(\chi^{2}=10.4, P=0.001\right)($ Table 1$)$.

\section{Obstetric history}

The mean inter-pregnancy interval between the last 2 pregnancies among the study population was 24.2 months: 23.8 months for cases and 24.7 for controls. Table 3 shows that the prevalence of birth interval < 18 months was higher in cases than controls $(47 \%$ versus $32 \%)\left(\chi^{2}=9.8, P<0.007\right)$.

There was a significant relationship between previous history of preterm delivery, with a higher prevalence for cases $(34.2 \%)$ than controls $(8.5 \%)$ (Table 3$)$. The mean number of the previous preterm deliveries was also significantly higher for cases than controls (2.04 versus 1.18$)(t=3.7, P<$ $0.001)$.

The prevalence of a positive history of stillbirth was higher among cases (11.1\%) than controls $(3 \%)\left(\chi^{2}=9.9, P<0.002\right)$ (Table 3)

Tables 3 also shows that $22.5 \%$ of cases had a positive history of CS delivery compared to $14 \%$ for controls $\left(\chi^{2}=4.8, P<\right.$ $0.028)$.

The prevalence of women with congenital gynaecological problems of the cervix and uterus was significant higher among cases $(3 \%)$ than controls $(1 \%)\left(\chi^{2}=6.8, P<\right.$ $=0.033)$. The main congenital gynaecological abnormalities present among the study population were septate uterus and cervical incompetence (data collected subjectively from the women).

\section{Regression analysis}

The logistic regression analysis showed the following factors were significant: maternal age $\geq 35$ years (OR $1.8,95 \%$ CI: $1-3, P$ $=0.04)$, refugee status (OR 1.57, 95\% CI: $1.05-2.34, P=0.026),<4$ antenatal visits (OR 2.4, 95\% CI: 1.4-4.1, $P=0.001$ ), medically induced pregnancy (OR $2.89,95 \%$ CI: $1.30-6.4, P=0.006)$, history of preterm delivery (OR $=5.58,95 \%$ CI: $3.13-9.94$, $P<0.001$ ), history of stillbirth (OR 4.01, $95 \%$ CI: $1.59-10.13, P=0.002)$ and history of CS (OR 1.78, 95\% CI: $1.00-3.00, P=$ 0.028) (Table 4).

\section{Discussion}

The present study was designed to investigate the maternal risk factors that contributed to preterm birth in the Gaza Strip. Although the mean maternal age among cases (27.0 years) was only slightly higher than controls (26.1 years), analysis by age 
Table 3 Comparison between cases and controls by selected maternal past obstetric history

\begin{tabular}{|c|c|c|c|c|c|c|c|c|}
\hline \multirow[t]{2}{*}{ Variable $^{a}$} & \multicolumn{2}{|c|}{ Cases } & \multicolumn{2}{|c|}{ Controls } & \multicolumn{2}{|c|}{ Total } & \multirow[t]{2}{*}{$\chi^{2}$-value } & \multirow[t]{2}{*}{$P$-value } \\
\hline & No. & $\%$ & No. & $\%$ & No. & $\%$ & & \\
\hline \multicolumn{9}{|c|}{ Interval between the last } \\
\hline$<18$ & 70 & 47.0 & 48 & 32.0 & 118 & 39.5 & 9.8 & 0.007 \\
\hline $18-23$ & 16 & 10.7 & 32 & 21.3 & 48 & 16.1 & & \\
\hline$>23$ & 63 & 42.3 & 70 & 46.7 & 133 & 44.5 & & \\
\hline \multicolumn{9}{|c|}{$\begin{array}{l}\text { History of previous } \\
\text { preterm birth }\end{array}$} \\
\hline Yes & 68 & 34.2 & 17 & 8.5 & 85 & 21.3 & 39.0 & 0.001 \\
\hline No & 131 & 65.8 & 183 & 91.5 & 314 & 78.7 & & \\
\hline \multicolumn{9}{|c|}{ History of stillbirth } \\
\hline Yes & 22 & 11.1 & 6 & 3.0 & 28 & 7.0 & 9.9 & 0.002 \\
\hline No & 177 & 88.9 & 194 & 97.0 & 371 & 93.0 & & \\
\hline \multicolumn{9}{|c|}{$\begin{array}{l}\text { History of previous } \\
\text { caesarean section }\end{array}$} \\
\hline Yes & 45 & 22.5 & 28 & 14.0 & 73 & 18.2 & 4.8 & 0.028 \\
\hline No & 155 & 77.5 & 172 & 86.0 & 327 & 81.8 & & \\
\hline \multicolumn{9}{|c|}{$\begin{array}{l}\text { Congenital gynaecological } \\
\text { problem }\end{array}$} \\
\hline Yes & 6 & 3.0 & 2 & 1.0 & 8 & 2.0 & 6.8 & 0.033 \\
\hline No & 185 & 93.4 & 196 & 98.5 & 381 & 96.0 & & \\
\hline Don't know & 7 & 3.5 & 1 & 0.5 & 8 & 2.0 & & \\
\hline
\end{tabular}

apercentages calculated out of total responses; missing data in some categories.

\begin{tabular}{|c|c|c|c|}
\hline Variable & Odds ratio & $95 \% \mathrm{Cl}$ & $P$-value \\
\hline Maternal age $\geq 35$ years & 1.80 & $1.00-3.00$ & 0.04 \\
\hline Refugee status & 1.57 & $1.05-2.34$ & 0.026 \\
\hline Medically induced pregnancy & 2.89 & $1.30-6.40$ & 0.006 \\
\hline$<4$ antenatal visits & 2.40 & $1.40-4.10$ & 0.001 \\
\hline History of preterm delivery & 5.58 & $3.13-9.94$ & 0.001 \\
\hline History of stillbirth & 4.01 & $1.95-10.13$ & 0.002 \\
\hline $\begin{array}{l}\text { History of caesarean section } \\
\text { delivery }\end{array}$ & 1.78 & $1.00-3.00$ & 0.028 \\
\hline
\end{tabular}


group revealed a significant positive relationship between age $\geq 35$ years and risk of preterm birth. These findings are similar to previous studies [4-6]. Kirz et al. explained this association by the presence of confounding factors such as pre-existing medical problems [7]. It is well known that maternal age $\geq 35$ years is linked to the occurrence of medical complications of pregnancy. The more advanced the maternal age, the more likely the pregnant woman is to develop pregnancy-related diseases such as pregnancy-induced hypertension and renal diseases that increase the risk of preterm birth, whether induced or spontaneous. The conclusion that maternal age $\geq 35$ years old is a risk factor for preterm birth calls for special focus to be paid to this age category through counselling and health education. Effective antenatal care, community health education and awareness campaigns, and encouraging the utilization of family planning services are tools that could decrease this problem.

One of the determinants of socioeconomic status that was investigated in this study was citizenship status. The study found that being a refugee increased the risk of preterm birth by 1.57 -fold and this could be related to the poor economic situation faced by refugees. Unfortunately, there are no studies available about the role of citizenship status as a contributor to preterm birth. However, most refugees have low family income, living in camps that are characterized by bad housing conditions that put pregnant women under social and economical stress that might contribute to preterm birth. There is a consensus in the literature regarding the role of low socioeconomic status in higher preterm birth rates [8]. Ancel et al. concluded that low educational level and unemployment of all household members was associated with twice the risk of very preterm birth [9].
Moreover, underprivileged social situation was significantly related to very preterm birth rather than moderate preterm birth [10]. Given that refugees form $58.3 \%$ of the total population in the Gaza Strip [11] and are living under diverse conditions, further studies should be conducted with a larger sample size to find out if refugee status plays an independent role for preterm birth or not.

Concerning the mode of conception, the present work revealed that medical intervention for conception (hormonal therapy and in vitro fertilization) increased the risk for preterm birth by almost 3-fold. The literature indicates that the use of ovulationinduction drugs and in vitro fertilization techniques are not only considered risk factors for preterm birth but are also linked to the increasing trends of preterm birth $[12,13]$. It may be that when women conceive after medical intervention the health providers tend to be anxious about the fetus and prefer to induce the pregnancy before it reaches fullterm, as a way of avoiding undesirable pregnancy outcomes. Further studies should be conducted to investigate if preterm birth occurs as result of the treatment or is medically induced.

The study revealed a significant negative relationship between the total number of antenatal care visits and having a preterm birth. The risk of preterm birth increased 2.4-fold among those who attended $<4$ visits than those who attended $\geq 4$ visits during the entire pregnancy period. This agrees with the literature which shows that that attending $<6$ prenatal care visits was significantly associated with preterm labour $[6,14,15]$. It is worth noting that a World Health Organization technical working group recommended a minimum of 4 antenatal visits for a woman with a normal pregnancy [16]. This confirms the importance of conducting population-oriented 
programmes encouraging attendance at antenatal care, focusing on the importance of early attendance. Health care systems need to develop and follow antenatal protocols in a way that increases the effectiveness of antenatal health services.

The study revealed a negative statistical relationship between maternal height and preterm birth, meaning that the taller the woman the less likely she was to have a preterm birth. There is inconsistency in the literature regarding the role of maternal height as a contributing factor for preterm delivery. Lao et al. found no significant relationship between maternal height and preterm birth [17], whereas Hacker and Moore found that maternal height $<152.3$ $\mathrm{cm}$ carried a greater risk of developing fetal pelvic disproportion, preterm labour and intrauterine growth retardation [18]. Gong also found an association between maternal height of $<158 \mathrm{~cm}$ and preterm delivery [15]. It is well known that short maternal stature and pelvic disproportion leads to CS delivery and possible prematurity. Further studies should be conducted with a larger sample size to find out if maternal height is an independent risk factor for preterm birth.

There was a higher total weight gain among cases than controls, meaning that adequate/normal weight gain during pregnancy decreases the risk of having a preterm birth regardless of the pre-pregnancy body mass index (BMI). This finding is supported by Schievel et al., who showed that the risk of preterm delivery is reduced by an adequate rate of weight gain during pregnancy even if the mother was underweight before pregnancy [19]. Health personnel who are caring for pregnant women should stress the importance of appropriate weight gain and adequate nutrition during pregnancy. Health education campaigns through the mass media, health promotion sessions and counselling could be helpful in this regard.

Several variables concerning past obstetric history were risk factors for preterm birth in this study. A short interval between the last 2 pregnancies $(<18$ months) was associated with an increased risk of preterm birth. There is inconsistency within the literature about the role of short interpregnancy interval and the risk of preterm birth. Zhu et al. concluded that the optimal inter-pregnancy interval for preventing adverse perinatal outcome is between 18 to 23 months. The risk of preterm birth for infants conceived $<6$ months after birth is greater than those who conceived $\geq 12$ months [20]. In contrast, Lieberman et al. found that a short inter-pregnancy interval, $<18$ months, is usually not linked to preterm birth but is associated with increasing risk of low birthweight [21]. This indicates the importance of conducting population-based programmes about the importance of spacing between pregnancies. The Islamic doctrine of breastfeeding children up to 2 years could be helpful in this regard within the Palestinian culture. The Palestinian health care system needs to assess the antenatal care offered and factors that encourage the utilization of antenatal services, such as offering the service free of charge, providing incentives, health promotion and adequate postnatal services.

A previous history of preterm birth was associated with a more than 5-fold increased risk of preterm birth and the chance of having preterm birth was increased by increasing number of previous preterm births. Khalil et al. found that history of preterm birth was associated with increasing the risk of recurrence of preterm birth [8]. According to a recent study carried out by Bloom et al. the risk of recurrence of preterm birth accounted for $10 \%$ of preterm births (OR 5.6) [22]. 
Mothers with a positive history of stillbirth had a 4-fold increased risk of having preterm birth than women who did not. In contrast, Khalil et al. found that history of stillbirth could not be considered as a risk factor for subsequent preterm birth [8].

The present work revealed a statistically significant positive relationship between the previous history of $\mathrm{CS}$ and having preterm birth. There is a consensus in the literature about the role of CS delivery as a contributing factor for preterm birth. According to a study conducted in Brazil by Bettiol et al., $\mathrm{CS}$ was the main contributor to the increasing rate of preterm birth rate [23]. They noted that the relationship between $\mathrm{CS}$ and preterm delivery was due to hypertensive disorders, placental abnormalities or cephalopelvic disproportion.

The presence of congenital gynaecological problems of the uterus and cervix, mainly septate uterus and cervical incompetence, increased the chance of having a preterm birth. Carroll et al. supported this finding and clarified that congenital uterine anomalies that are implicated in preterm delivery include unicornuate, septate and bicornate abnormalities [5]. Therefore, women with any congenital gynaecological problems need further attention and counselling and should be regarded as having high-risk pregnancies.

To summarize, the risk factors for preterm birth were: older maternal age, being a refugee, inadequate antenatal care, failure to gain adequate weight during pregnancy and previous history of preterm birth. Other significant risk factors were: short stature, short interval between the last 2 pregnancies, presence of congenital gynaecological abnormalities, previous history of caesarean delivery and previous history of stillbirth. We can infer from this that poor economic status, high fertility and lack of awareness among the women regarding proper nutrition during pregnancy predispose women for preterm birth in the Gaza Strip. Therefore, it is necessary to conduct an appropriate prevention programme to reduce the incidence of preterm birth in the Gaza Strip.

Based on the findings of the study we recommend that a definition for preterm birth needs to be agreed with a precise cutoff point distinguishing between abortion and preterm delivery. Furthermore, there is a need to revise/utilize the recently developed protocols for antenatal, natal and postnatal care. This could include early diagnosis of possible risk factors. Finally, further studies should be conducted with a larger sample size to verify the findings of this study. More focused studies need to be conducted that tackle certain group of variables independently, such as demographic variables and familial tendency for preterm birth.

\section{Acknowledgements}

This paper is part of a thesis submitted in partial fulfilment of the requirements for the Degree of Master of Public Health through the School of Public Health, Al-Quds University, Gaza, Palestine, 2003.

\section{References}

1. Arafa M et al. Maternal hemoglobin and premature child delivery. Eastern Mediterranean health journal, 1998, 4(3):480-6.

2. Kramer MS et al. Secular trends in preterm birth: a hospital-based cohort study.
Journal of the American Medical Association, 1998, 280(21):1849-54.

3. Copper RL et al. A multicenter study of preterm birth weight and gestational age specific neonatal mortality. American jour- 
nal of obstetrics and gynecology, 1993, 168:78-84

4. Berkowitz GS, Papiernik E. Epidemiology of preterm birth. Epidemiologic review, 1993, 15(2):414-34.

5. Carroll SG, Sebire NJ, Nicolaides $\mathrm{KH}$. Preterm prelabour amniorrhexis. New York, Parthenon, 1996

6. Helias FL, Ancel PY, Blondel B. Risk factors for prematurity in France and comparisons between spontaneous prematurity and induced labor: results from the National Perinatal Survey 1995. Journal of obstetrics and biological reproduction, 2000, 29(1):55-65.

7. Kirz DS, Dorchester W, Freeman RK. Advanced maternal age: the mature gravida. American journal of obstetrics and gynecology, 1985, 152:7-12.

8. Khalil KA et al. Pattern of growth and development of premature children at the age of two and three years in Alexandria Egypt (Part II). Eastern Mediterranean health journal, 1995, 1(2):186-93.

9. Ancel PY et al. Very and moderate preterm birth: are the risk factors different? British journal of obstetrics and gynecology, 1999, 106(11):1162-70.

10. Ancel PY et al. Social differences of very preterm birth in Europe: interaction with obstetric history. American journal of epidemiology, 1999, 149(10):908-15.

11. The status of health in Palestine: annual report 2001. Ramallah, Palestine, Ministry of Health, 2002.

12. Shenker JG, Yarkoni S, Granat M. Multiple pregnancies following induction of ovulation. Fertility and sterility, 1981, 35:105-23.

13. Hecht BR. The impact of assisted reproductive technology on the incidence of multiple gestation. In: Keith LG et al., eds. Multiple pregnancy, epidemiology gesta- tion and perinatal outcome. New York, Parthenon, 1995

14. Rodrigues T, Barros H. Factores de risco para trabalho de parto pre-termo. [Risk factors for preterm labor.] Acta medica portuguesa, 1998, 11(10):901-5.

15. Gong JH. [Preterm delivery and its risk factors.] Zhonghua fu chan ke za zhi, 1992, 27(1):22-4 [in Chinese].

16. Antenatal care. Report of a technical working group. Geneva, World Health Organization, 1994 (WHO/FRH/MSM/968).

17. Lao TT, Pun TC. Preterm birth unrelated to maternal height in Asian women with singleton gestations. Journal of the Society for Gynaecologic Investigation, 2001, 8(5):291-4.

18. Hacker NF, Moore JG. Essentials of obstetrics and gynecology. Philadelphia, WB Saunders Company, 1998.

19. Schieve LA et al. Pre-pregnancy body mass index and pregnancy weight gain: association with preterm delivery. Obstetrics and gynecology, 2000, 96(2):194200.

20. Zhu BP et al. Effect of the interval between pregnancies on perinatal outcomes New England journal of medicine, 1999, 340(8):589-94.

21. Lieberman $\mathrm{E}$ et al. The association of interpregnancy interval with small for gestational age births. Obstetrics and gynecology, 1989, 74:1-5.

22. Bloom SL et al. Recurrence of preterm birth in singleton and twin pregnancies Obstetrics and gynecology, 2001, 98(3):379-85.

23. Bettiol $\mathrm{H}$ et al. Factors associated with preterm births in Southeast Brazil: a comparison of two birth cohorts born 15 years apart. Paediatric and perinatal epidemiology, 2000, 14(1):30-8. 